\title{
Cardiogenic Shock
}

\author{
Elias Knobel
}

São Paulo, SP - Brazil

Cardiogenic shock remains a condition with a high mortality rate, varying from $30 \%$ to $90 \%$, despite the great advances like thrombolytic therapy, development of several methods of partial or total artificial circulatory support, and of heart transplantation that have been made in the last two decades in the treatment of heart diseases ${ }^{1}$. Recently published data from 36 centers worldwide that participated in the Shock Trial Registry, reported that 1,380 patients admitted in the acute phase of acute myocardial infarction (AMI) had a $63 \%$ mortality in the hospital phase ${ }^{2}$.

This complex clinical syndrome may have multiple causes, may be of acute occurrence or may be the final expression of the evolution of chronic ventricular dysfunction. Recently, an increase in the number of patients with ventricular dysfunction, directly related to the increase in the mean age of the population, has been observed. The introduction of new therapies, such as the use of thrombolysis in AMI, ACE inhibitors, and beta-blockers for patients with heart failure (HF), has also contributed to that increase ${ }^{3-5}$.

\section{Definition}

Cardiogenic shock is a condition of systemic tissue hypoperfusion due to heart muscle incapacity to provide adequate output for organism needs ${ }^{6}$. The shock is cardiogenic when the primary cause is heart dysfunction. The clinical diagnosis of cardiogenic shock is made in the presence of hypotension (systolic blood pressure (SBP) $<90 \mathrm{mmHg}$ or $30 \mathrm{mmHg}$ below the basal value) and evidence of tissue hypoperfusion, such as oliguria, cyanosis, cold limbs, and alterations in the consciousness level. Persistence of the shock status after correction of myocardial and extracardiac factors that contribute to the reduction of tissue perfusion, such as hypovolemia, arrhythmias, hypoxia, metabolic and acid-base balance disorders, confirm the diagnosis of cardiogenic shock. When invasive hemodynamic monitoring is available, diagnosis is made if the following alterations are found ${ }^{4}$ (the following values vary in the medical literature): $\mathrm{SBP}<90 \mathrm{mmHg}$; pulmonary capillary pressure $>18 \mathrm{mmHg}$; cardiac index $<1.81 / \mathrm{min} / \mathrm{m}^{2}$; systemic vascular resistance index $>2000 \mathrm{dyne} / \mathrm{s} / \mathrm{cm}^{5} / \mathrm{m}^{2}$; increase in the arteriovenous oxygen content difference $>5.5 \mathrm{ml} / \mathrm{dL}$.

\section{Etiology}

Despite being found in several clinical situations, such as myocardial failure due to sepsis or pancreatitis, rupture of tendinous cords or valve secondary to endocarditis, myocarditis, rejection following heart transplantation, rupture or thrombosis of valve prosthesis, and ventricular or supraventricular arrhythmias producing low output, the main etiology of this condition is heart muscle loss by AMI. In the 70's, Mirowski et $\mathrm{al}^{7}$, in a community hospital, observed that, from 1,246 patients admitted consecutively with a diagnosis of AMI, $12 \%$ developed cardiogenic shock, with a hospital mortality rate of $87 \%$. Comparing patients with AMI complicated by cardiogenic shock and those not in shock, the former were older, with infarction in the anterior wall, and frequent history of previous infarction, angina and $\mathrm{HF}^{8-10}$. Other studies also show that those who develop shock after hospital admission are generally diabetic, older, female patients and have a history of previous infarction, with high levels of cardiac enzymes, mainly CKMB, and anterior infarction ${ }^{11,12}$. Wo-men showed greater predisposition to cardiogenic shock in the recent Shock Trial Registry ${ }^{2}$.

In the MILIS (Multicenter Investigation of Limitation of Infarct Size - 1989) study ${ }^{13}$ performed in the prethrombolytic era, age $>65$ years, ejection fraction $<35 \%$, CKMB peak greater than $160 \mathrm{IU} / \mathrm{l}$, diabetes mellitus and previous infarction were considered predictive and independent factors for the development of cardiogenic shock. The chance of developing cardiogenic shock in the presence of all these factors can reach 54\%. In this study, the incidence of cardiogenic shock after hospitalization was $7.1 \%$. Data extracted from this multicenter study show that, in the patients with AMI, $1.5 \%$ to $2.5 \%$ arrived at the hospital in cardiogenic shock, and $7.1 \%$ developed it during the first days of hospitalization. The ISIS-3 (International Study of Infarct Survival 3), TIMI IIIB (Thrombolysis in Myocardial Infarction IIIB Study) and GUSTO (Global Use Strategies to Open Occluded Arteries in Acute Coronary Syndromes) 
studies ${ }^{14-16}$ report similar incidences of cardiogenic shock development among patients admitted with AMI (7.0\%, $5.1 \%$ and $6.1 \%$, respectively). In general, cardiogenic shock occurs in $5 \%$ to $10 \%$ of the cases of AMI.

\section{Pathophysiology}

From a major coronary artery occlusion and loss of a significant amount of myocardial mass, a series of vicious cycles are triggered that, if perpetuated, culminate in shock, failure of multiple organs and systems, and death (fig. 1).

Hypotension resulting from muscle mass loss may cause hypoperfusion of still viable myocardial areas, contributing to aggravation of the ventricular function. It is estimated that a minimum loss of $40 \%$ of the left ventricular mass is necessary for genesis of cardiogenic shock ${ }^{17,18}$. The loss of ventricular mass may be a consequence of a great infarction in previously healthy patients, of small losses in previously infarcted patients, or of large ischemic areas with little necrosis in patients with advanced coronary atherosclerotic disease ${ }^{3}$. Compensatory mechanisms, such as the activation of the autonomic nervous system and the reninangiotensin-aldosterone system, promote increase in heart rate, reflex vasoconstriction, sodium and water retention, thus elevating the myocardial oxygen consumption ${ }^{6,19}$. The persistence of low cardiac output ends up accentuating hypoxia, with accumulation of metabolites, acidosis, and endothelial and cellular damage. This mechanism also favors heart arrhythmias, which impair even more the cardiac performance and may even lead to death. Failure of multiple organs is the endpoint of this pathophysiological situation.

From patients developing cardiogenic shock in the acute phase of AMI, 10-30\% do it in the first $24 \mathrm{hrs}^{16,20}$, and the cardiogenic shock relates to the extensive loss of muscle mass. In patients developing it after the $1^{\text {st }}$ day, a complex relationship between necrotic and viable areas accounts for a sequence of events. The extension, expansion and aneurysm formation change ventricular volumes and geometry, increase stress and oxygen consumption by the myocardium, as well as jeopardize coronary perfusion ${ }^{21}$ (tab. I). Observation of Frank-Starling curves in this group of patients reveals that, for similar left ventricle (LV) filling pressures, the cardiac index developed is much lower than in patients without loss of ventricular mass ${ }^{22}$. In addition, there is lower ventricular compliance, so that small eleva-

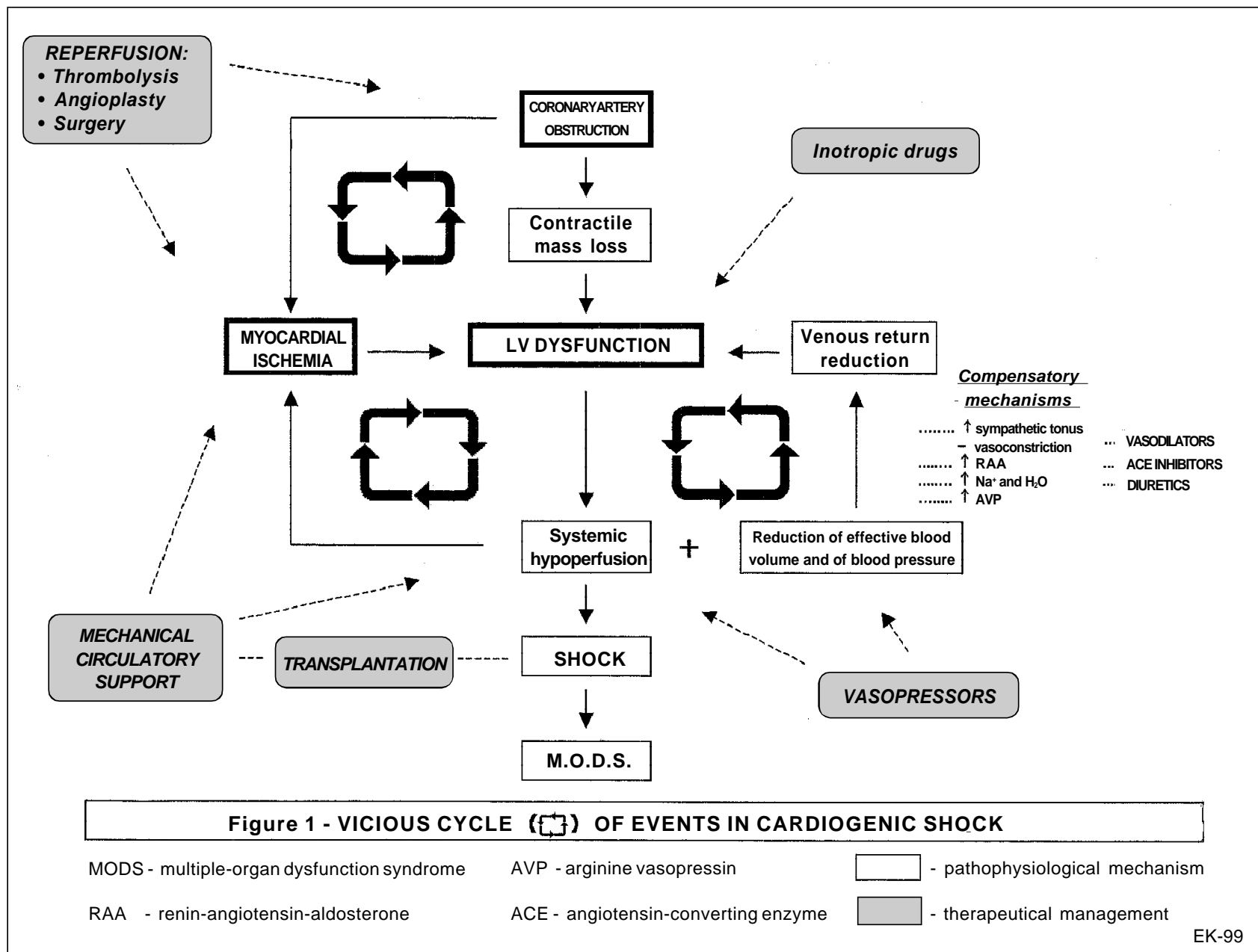

Fig. 1 - Vicious cycle of events in cardiogenic shock. 
tions in the LV diastolic volume cause great increase in the final diastolic pressure, liquid extravasation into the pulmonary interstitium and little increase in the cardiac index.

\section{Clinical Aspects}

Patients show signs and symptoms of low cardiac output $(\mathrm{CO})$ associated with variable degrees of pulmonary congestion. Cold sweating, mental confusion, oliguria, tachycardia and filiform acceleration of the pulse, and hypotension with approximation of the systolic and diastolic levels of BP are often found and reflect the low output.

Pulmonary congestion leads to hypoxemia and $\mathrm{CO}_{2}$ retention, and hence, to worsening of myocardial and cerebral oxygenation, resulting in the appearance of mental confusion and cardiac arrhythmias. Presence of the $3^{\text {rd }}$ heart sound, muffled heart sounds, jugular venous distention and variable degrees of pulmonary rales are also often found on physical examination. The appearance of cardiac murmurs, initially absent, is important to establish the diagnosis of post-AMI mechanical defects (ventricular septal defect, papillary muscle dysfunction) and in the complications of infectious endocarditis. The echocardiogram is helpful in providing data on global and regional ventricular function, integrity of valve function, and presence of intracardiac shunts and of pericardial effusion ${ }^{23}$.

\section{Invasive and metabolic hemodynamic monitoring}

Invasive monitoring with the Swan-Ganz catheter allows the differential diagnosis with other situations of low output and, mainly, a fast and precise evaluation of the therapeutic maneuvers adopted.

Use of vasodilators and diuretics in high doses in a patient with AMI may cause low output symptoms with low filling pressures. Some patients initially diagnosed as having cardiogenic shock respond to volume reposition, characterizing the condition of hypovolemia. Clinical and hemodynamic evaluation allow the distinction of patients according to the Killip-Kimball heart failure classification ${ }^{20}$ and Forrester et $\mathrm{al}^{24}$, which has therapeutic and prognostic implications (tab. II).

The determination of the gastric intramucosal $\mathrm{pH}(\mathrm{pHi})$ (or, more appropriately, $\mathrm{pCO}_{2}$ gap) by gastrointestinal tonometer allows a regional evaluation of the adequacy of tissular oxygenation and detection of mucosal ischemia, before the development of ischemic lesions of magnitude sufficient to allow the translocation of enteric bacteria and their toxins ${ }^{25}$. This sequence of events triggered by a selective reduction in the oxygen transportation to the splanchnic organs in shock situations tends to prioritize the "vital organs", the heart and brain. Many patients with cardiogenic shock, after improvement and recovery of cardiac performance, may have evidence of compromise of the splanchnic region due to the prolonged hypoperfusion. Mesenteric ischemia, allowing bacterial translocation, enhances the morbid process by promoting further reduction in oxygen transportation, either through hypovolemia, myocardial depression, hypoxemia, increase in metabolic demand, or by stressing the inadequate distribution of the flow, resulting in impairment of the tissue capacity of $\mathrm{O}_{2}$ extraction. Establishment of a normal pHi (7.32) (i.e., a proper $\mathrm{pCO}_{2}$ gap) as an objective in the resuscitation of patients in shock may contribute to adequate further blood volume replacements or alterations in vasoactive drugs ${ }^{25}$.

The administration of inotropic drugs such as dobutamine has been used to optimize $\mathrm{O} 2$ transportation. There is recent evidence that doses much higher than the usual ones are required to reverse intramucosal ischemia. Tonometry may help in the titration of these drugs. In some circumstances, accentuation of intramucosal acidosis was shown with dobutamine infusion, probably due to flow redistribution to other areas than the splanchnic ones ${ }^{26}$.

\footnotetext{
Table I - Pathophysiological mechanisms involved in cardiogenic shock

Acute myocardial infarction

Left ventricle myocardium loss at a critical level

Right ventricle failure

Mechanical complications

1) Acute mitral regurgitation due to rupture or dysfunction of the papillary muscle.

2) Rupture of the interventricular septum

3) Rupture of the left ventricular wall

4) Left ventricle aneurysm.

Other conditions

1) End stage cardiomyopathy.

2) Myocardial contusion.

3) Acute myocarditis.

4) Obstruction of the left ventricular outflow tract.

5) Aortic stenosis.

6) Obstructive hypertrophic cardiomyopathy.

7) Obstruction of the inlet of the left ventricle.

8) Mitral stenosis.

9) Atrial myxoma or thrombosis

10) Cardiopulmonary bypass sequela
}

\begin{tabular}{|c|c|c|}
\hline \multicolumn{3}{|c|}{$\begin{array}{c}\text { Table II - Clinical and hemodynamic subgroups in acute } \\
\text { myocardial infarction }\end{array}$} \\
\hline $\begin{array}{l}\text { Killip } \\
\text { Subgroup }\end{array}$ & $\begin{array}{l}\text { Clinical } \\
\text { characteristics }\end{array}$ & $\begin{array}{l}\text { Hospital } \\
\text { mortality }\end{array}$ \\
\hline I & No congestion signs & $<6 \%$ \\
\hline II & $\mathrm{S} 3$, basal rales & $<17 \%$ \\
\hline III & Acute pulmonary edema & $38 \%$ \\
\hline IV & Cardiogenic shock & $81 \%$ \\
\hline $\begin{array}{l}\text { Forrester } \\
\text { subgroup }\end{array}$ & $\begin{array}{l}\text { Hemodynamic } \\
\text { characteristics }\end{array}$ & $\begin{array}{l}\text { Hospital } \\
\text { mortality }\end{array}$ \\
\hline I & PCP $<18$, IC $>2.2$ & $3 \%$ \\
\hline II & $\mathrm{PCP}>18, \mathrm{IC}>2.2$ & $9 \%$ \\
\hline III & PCP $<18$, IC $<2.2$ & $23 \%$ \\
\hline IV & PCP $>18$, IC $<2.2$ & $51 \%$ \\
\hline
\end{tabular}


Study of the aerobic metabolism by means of indirect calculation of oxygen supply $\left(\mathrm{DO}_{2}\right)$ and consumption $\left(\mathrm{VO}_{2}\right)$ may be performed at bedside, using the Swan-Ganz catheter and indirect calorimetry. The profile found in this situation shows a high oxygen extraction rate $\left(\mathrm{EO}_{2}\right)$ due to a reduction in the $\mathrm{O}_{2}$ supply (low output) and an increase in its consumption due to the stress situation. Sequential follow-up of oxygen metabolism allows evaluation of the adequacy of the therapeutics employed ${ }^{27}$.

Inadequate tissue perfusion leads to metabolic acidosis detected through blood gas analysis or, earlier, through the elevation of the serum levels of lactate. This situation is potentially deleterious because it causes a reduction in the cardiac contractility, in the cardiac index and in the peripheral vascular responsiveness. It also causes the appearance of ventricular arrhythmias or makes the already existing arrhythmias more difficult to control.

\section{Treatment}

Treatment aims to maintain a CO level suitable for the basic needs of the organism and to reduce the loss of ischemic myocardium at risk ${ }^{28,29}$.

The result of the clinical treatment isolated in cardiogenic shock is extremely unfavorable. In-hospital mortality is greater than $70 \%$, and patients being discharged have a low survival expectation due to the degree of the resulting HF.

In a didactic manner, we can sketch the treatment of cardiogenic shock as follows: A) general support measures; B) pharmacological treatment; C) mechanical circulatory support; D) coronary artery reperfusion; E) surgical treatment.

\section{General support measures}

1) Pain control - Control of pain will reduce myocardial oxygen consumption and levels of serum catecholamines. Pain control should be achieved as early as possible to prevent myocardial damage. Morphine sulfate and/or meperidine is used intravenously, and special attention should be paid to blood pressure levels because this medication may cause severe hypotension with further impairment of coronary perfusion.

2) Mechanical oxygenation and/or ventilation-Oxygen administration by nasal catheter with 2 to $31 /$ min provides a greater oxygen supply to the tissues. Control of the blood gases must be made for therapeutic optimization. If required, mechanical ventilation should be installed, providing a reduction in oxygen consumption by thoracic muscles.

3) Sedation - Many times, in addition to analgesia, sedation with intravenous alprazolam or diazepam is necessary, at a dose of $5 \mathrm{mg}$ or greater, as required.

4) Treatment of arrhythmias, metabolic acidosis and/ or hypovolemia - These conditions may contribute to shock and, when corrected in time, the patient's hemodynamic state can be reversed, influencing the prognosis.

\section{Pharmacological treatment}

Inotropic and vasopressor agents - The drugs most used in the treatment of these patients are the sympathomimetic amines ${ }^{30}$. They must be administered in the presence of tissular hypoperfusion, after properly restoring the intravascular volume.

Norepinephrine must be the first-choice agent to be employed whenever there is severe arterial hypotension (systemic systolic BP $<70 \mathrm{mmHg}$ ). Immediate reversion of these pressure levels is fundamental in the maintenance of coronary artery perfusion pressure, because of the interaction with alpha and beta-adrenergic receptors. Its artery action on beta-adrenergic receptors increases the myocardial contractility and the velocity of conduction of the cardiac stimulus in the heart chronotropism. However, the alphaagonist effect is predominant at the doses and for the purpose norepinephrine is used for. Doses between 2 and $15 \mu \mathrm{g} / \mathrm{kg} / \mathrm{min}$ cause peripheral vasoconstriction with significant increase in the total and regional systemic arterial resistance, with perfusion impairment of organs, such as kidneys, bowel, lungs, skeletal muscles and skin. Reflex bradycardia may occur due to an increase in the mean pressure of the aorta and subsequent reduction in $\mathrm{CO}$.

In those situations where hypotension is not so significant, dobutamine is the agent of choice. This drug has the ability to stimulate alpha- 1 and beta- 1 and 2 adrenergic receptors. Its positive inotropic and chronotropic actions do not depend on endogenous release of norepinephrine like those of dopamine. Dobutamine hemodynamic effects are dose-dependant. Doses up to $15 \mu \mathrm{g} / \mathrm{kg} / \mathrm{min}$ increase myocardial contractility with no significant elevation of the heart rate, and also increase the diastolic coronary flow and the collateral flow to ischemic areas ${ }^{31,32}$.

In general, there is reduction in the central venous and capillary pulmonary pressures due to better heart performance, with no change, however, in pulmonary vascular resistance. Dobutamine doses higher than $30 \mu \mathrm{g} / \mathrm{kg} / \mathrm{min}$ must be avoided because they favor the appearance of ventricular arrhythmias, in addition to other undesirable side effects, such as the accentuated increase in myocardium oxygen consumption. It should be stressed that dobutamine may promote a reduction in peripheral arterial resistance and systemic pressure through its interaction with vascular beta-adrenergic receptors, which sometimes leads to its association with other vasopressor drugs, such as norepinephrine. As previously mentioned, this drug must not be prescribed to patients with severe arterial hypotension, particularly when one intends to adjust its dosage to pressure levels, when norepinephrine must be first employed.

Dopamine may also be used, mainly when moderate hypotension and hypoperfusion are associated, because its dosage may be set to allow an increase in the inotropism with discrete peripheral vasoconstriction. At low doses of 1 
to $3 \mu \mathrm{g} / \mathrm{min}$ (dopaminergic effect), it causes renal vasodilation, in addition to mild positive inotropic action. At doses up to $10 \mathrm{mg} / \mathrm{kg} / \mathrm{min}$, it produces effects related to the stimulation of beta-1-adrenergic receptors. Higher doses produce additional inotropic effect, but at the expense of a progressive increase in heart rate and oxygen consumption. High doses of dopamine increase pulmonary artery pressure, raising $L V$ preload and right ventricle $(R V)$ afterload ${ }^{30}$.

Phosphodiesterase inhibitors increase myocardial inotropism by a different pathway from adrenergic stimulation, favoring an increase in $\mathrm{CO}$ and a decrease in pulmonary capillary pressure by a positive inotropic action associated with peripheral vasodilation. There is no evidence that their use produces better effects than that of sympathomimetic drugs, and currently they are used as additional therapeutics in refractory cases.

It should be emphasized that most of these phosphodiesterase-inhibitor drugs should be used only in the acute phase of the cardiogenic shock, serving as a bridge to a definitive treatment, either surgical or otherwise. Their chronic use did not show benefits and even caused, in some groups of patient, higher mortality when compared with control individuals ${ }^{33-35}$. Enoximone has similar effects, acting like phosphodiesterase inhibitors, improving myocardial contractility and causing dilation of vascular smooth muscles ${ }^{36}$. ACE inhibitors, even though available for intravenous use, have a prolonged action period, which makes their withdrawal difficult if deleterious effects occur after their introduction. Digitalis may worsen the hemodynamic condition of the patient, because it causes peripheral vasoconstriction and may increase oxygen consumption ${ }^{33}$. Digitalis has been reserved for control of atrial tachyarrhythmias. Antiarrhythmics must be administered rapidly to control supraventricular or ventricular arrhythmias that may reduce $\mathrm{CO}$ or increase myocardial oxygen consumption. The preferred drug, which has little negative inotropic action, is amiodarone.

It should be noted that, in patients with cardiogenic shock due to RV infarction, dobutamine is preferred to dopamine, due to its beneficial effects in the pulmonary vasculature. In these patients, the basic therapeutics consists of restoring left ventricular filling pressure through volume infusion, sinus rhythm maintenance, or use of sequential atrioventricular pacemaker in those patients with atrioventricular block (AVB) ${ }^{37-39}$.

Vasodilators - Vasodilators are useful drugs in diminishing ventricular preload and afterload, reducing pulmonary congestion and facilitating ventricular emptying, in addition to decreasing myocardial oxygen consumption. The main problem related to the use of these drugs is hypotension, which may enhance pathophysiological mechanisms aggravating the shock and reducing coronary and cerebral flows even more. The preferred vasodilators are those of intravenous administration, which may be rapidly withdrawn, if necessary. Nitroglycerine is less potent than sodium nitroprusside as an arteriolar vaso- dilator ${ }^{40}$, but has the advantage of not producing flow steal, i.e., deviation of the coronary flow to nonischemic vascular regions ${ }^{41}$. Sodium nitroprusside may be used, beginning with a dose of $0.5 \mathrm{mg} / \mathrm{kg} / \mathrm{min}$, acting mainly in the arteriolar region, causing a significant reduction in systemic resistance. Vasodilators are particularly important when mitral regurgitation plays a significant role in the pathophysiological process.

Diuretics - Considered as a first-choice drug in patients with LV failure and pulmonary congestion, diuretics must be used carefully because an overdose may lead to a hypovolemic condition with consequent significant reduction in LV filling pressure, especially in elderly individuals. This management will be facilitated through hemodynamic monitoring by the Swan-Ganz catheter. A PCP must be kept within 14 and $20 \mathrm{mmHg}$. Intravenous furosemide is routinely used.

Other drugs - Acetylsalicylic acid reduces mortality and reinfarction in the acute phase of myocardial infarction. It must be routinely administered, although its effectiveness has not yet been tested in this patient subgroup. Full heparinization is also indicated ${ }^{28,29}$, for reducing the formation of left intraventricular thrombi, deep venous thrombosis and the propagation of intracoronary thrombi.

Association of drugs - In cardiogenic shock, it is often necessary to use two or more drugs to obtain a better therapeutic result. The use of invasive monitoring allows finding the ideal combination of drugs rapidly, minimizing the additional loss of cardiac muscle and the impairment of other organs.

\section{Mechanical circulatory support}

Mechanical cardiac support is indicated in all situations where it is not possible to maintain $\mathrm{CO}$ adequate for organic needs ${ }^{42,43}$. The advantage of mechanical support is to allow an adequate perfusion pressure in the coronary arteries with fewer vasoactive drugs or, even, none at all ${ }^{44}$.

The use of circulatory assist devices may be the only therapeutic alternative in cases of great loss of ventricular mass. The most used device is the intraaortic balloon pump (IABP), based on the counterpulsation principle to increase $\mathrm{CO}$. A balloon-catheter is placed in the thoracic aorta, so that its distal end is located just below the emergence of the left subclavian artery. Synchronically with the electrocardiogram (ECG), the balloon is inflated during ventricular diastole and deflated during systole, causing an increase in the perfusion pressure of the coronary arteries and facilitating blood flow into tissues. In addition, the fast deflation of the balloon during systole causes a "vacuum" effect that reduces the impedance of the $\mathrm{LV}$ outflow tract, facilitating LV emptying. This reduction in the afterload causes a $10 \%$ reduction in myocardial oxygen consumption. $\mathrm{CO}$ may be risen $10 \%$ to $20 \%$, depending on LV contractility, infarction 
extension, and myocardial ischemia. The presence of cardiac arrhythmias impairs the use of this device, because they make synchronization difficult.

In clinical practice, the IABP has been used in nonsurgical patients with cardiogenic shock or low $\mathrm{CO}$, in patients awaiting cardiac surgery, and in some patients before heart transplantation. But even in more advanced centers, it has been used less than would be expected ${ }^{45}$.

A great cooperative study ${ }^{46}$ showed that IABP in patients in cardiogenic shock, in the pre-thrombolytic era, restored hemodynamic stability, improved or maintained the function of target organs and improved myocardial metabolism evaluated by the reduction in its lactate production. However, the mortality of these patients was still very $\operatorname{high}(83 \%)$.

The PAMI-II study, which evaluated the effects of IABP prophylactically employed in AMI patients stratified as high risk, showed that, despite being safe, it did not reduce the occurrence of death, recurrent infarction, coronary reocclusion, cerebral stroke $(\mathrm{CS})$ or $\mathrm{HF}^{47}$.

Other techniques of mechanical circulatory support are available but are still being evaluated and, therefore, their use is limited to certain centers.

The assistance devices that replace ventricular decrease function, such as centrifugal pumps, extracorporeal circulation circuits used in cardiac surgery and artificial ventricles, are indicated if IABP is not sufficient to stabilize the patient. Among them, we can cite uni or biventricular assist devices, installation of percutaneous cardiopulmonary bypass support ${ }^{48}$ and the hemopump. All of these cause a significant increase in $\mathrm{CO}$, reverse metabolic disorders and restore the function of organs compromised by low output, but they are still considered procedures serving as a "bridge" to myocardial revascularization (angioplasty and revascularization surgery).

Mechanical support must not be delayed by "maximum" clinical attempts to control low output; delay in indicating IABP or other devices contributes to the high mortality seen in this situation.

\section{Coronary reperfusion}

Thrombolysis - The use of thrombolytic agents to restore coronary permeability significantly reduces mortality in $\mathrm{AMI}^{49,50}$. Reperfusion, when instituted early, limits myocardial damage, improves ventricular function and promotes electrical stability. Late reperfusion may also be beneficial, favoring ventricular scaring and remodeling.

The thrombolytic agent and the way it is administered seem to be important in reducing cases of cardiogenic shock. ISIS-3 study, which compared the administration of three agents (streptokinase, t-PA and APSAC), did not show any difference among them in reducing cases of cardiogenic shock ${ }^{51}$. However, in the GUSTO study ${ }^{52}$, where t-PA was administered using a faster infusion, a greater speed in coronary reperfusion rates was obtained, probably resulting in a smaller incidence of cardiogenic shock $(5.1 \% \times 6.6 \%, \mathrm{p}<0.05)$. The development of new thrombolytic and adjuvant agents (platelet glycoprotein $\mathrm{IIb} / \mathrm{III}$ inhibitors) should favor these patients even more ${ }^{53}$.

However, for AMI patients in cardiogenic shock at their initial evaluation, the benefit of thrombolytic agents is less obvious, with reports of smaller efficiency ${ }^{49}$. Hypoperfusion, mainly of the coronary artery, is apparently responsible for it. Concomitant use of vasopressor agents and IABP increases coronary reperfusion rates ${ }^{54}$. Contrarily, the study published by the Fibrinolytic Therapy Trialist Collaborative Group, compiling data from the most important randomized, placebo-controlled studies on thrombolysis in AMI, showed an important reduction in mortality (seven lives saved for each thousand treated) for AMI patients who presented, at admission, with systolic systemic BP $<100 \mathrm{mmHg}$ and heart rate $>100 \mathrm{bpm}^{55}$.

\section{Mechanical reperfusion}

High cardiogenic shock mortality due to clinically treated AMI led to attempts to modify the natural history of this situation through the use of interventions that allow reperfusion of the culprit artery and decrease of the culprint lost ventricular muscle loss.

Percutaneous transluminal coronary angioplasty (PTCA) has been shown to be an alternative to chemical reperfusion in AMI patients ${ }^{56-58}$. In the PAMI-I study, primary PTCA was associated with a smaller occurrence of cerebral strokes (CS), recurrent ischemia, and the combination of death and AMI events. Patients considered at high risk exhibited the greatest benefits. In the same way, the GUSTO II-B study showed a reduction in the combined endpoints of death, reinfarction and CS in patients undergoing mechanical reperfusion, when compared with those on chemical thrombolysis ${ }^{59}$.

However, there is no report of a randomized study that specifically compares, patients in cardiogenic shock treated with PTCA versus chemical reperfusion. Several nonrandomized studies have shown the advantage of this therapeutic modality by significantly reducing mortality indices. A data compilation of 433 patients with a diagnosis of post-AMI cardiogenic shock shows that PTCA produced arterial reperfusion in $73 \%$ of the patients and the mortality rate in this group was $31 \%$. In patients with reperfusion failure, the mortality rate was $81 \%{ }^{60}$. Detailed analysis of patients referred for PTCA shows a selection bias because it represents a group of patients with less severe symptoms.

The GUSTO I study showed that $88 \%$ of 1,321 AMI patients (within 36,333 randomized ones) developing cardiogenic shock and remaining alive after 30 days survived at least for one year ${ }^{61}$. Among them, survival at the end of one year was $91.7 \%$ for those revascularized in a 30day period and $85.3 \%$ for those not reperfused $(\mathrm{p}=0.0003)$. Preliminary data from the Shock Trial Registry revealed that, in the group of 485 revascularized patients, the mortality rate was smaller (41 vs $79 \%, \mathrm{p}<0.001$ ) than in the group that underwent clinical treatment ${ }^{2}$. 
Considering the definitive results of the randomized study referred to above, the actual role of myocardial revascularization in patients in cardiogenic shock due to AMI should provide an important contribution to comparing clinical treatment, PTCA and surgical revascularization. However, while these results are expected, percutaneous treatment must be indicated, as long as possible, for patients in cardiogenic shock. When this procedure is not available, the patient must receive a thrombolytic agent (preferably, t-PA in an accelerated regimen) and be transferred to another institution where cardiac catheterization can be performed.

The concept still prevailing is that patients with AMI and in cardiogenic shock must undergo early cardiac catheterization and angioplasty or surgery, still in the first hours of evolution, before myocardial and systemic damage progresses to an irreversible point.

\section{Surgical treatment}

Despite lower mortality rates than that in medically treated cases, a significant perioperative mortality is still seen in myocardial revascularization surgery (about 40\%), especially when compared with the mortality rate of elective surgeries ${ }^{62}$. Myocardial revascularization surgery has the potential advantage of promoting a more complete revascularization but it is a procedure not always easy to be implemented due to the complexity of necessary resources. Some ongoing studies report the effectiveness of surgical revascularization with an improvement in survival in post-AMI cardiogenic shock ${ }^{63}$.

Myocardial revascularization surgery should be the therapeutics of choice in cases of cardiogenic shock secondary to mechanical defects, such as rupture of the interventricular septum, ischemic mitral dysfunction, and cardiac tamponade due to ventricular free wall rupture.

\section{Cardiogenic shock due to right ventricle infarction}

Cardiogenic shock may be related to RV mechanical (rupture of the interventricular septum, rupture of the RV free wall, or rupture of the papillary muscle of the tricuspid valve) or electrical (total atrioventricular block or other atrioventricular conduction disorders) complications or with low $\mathrm{RV}$ output associated with muscle loss.

RV infarction takes place in about $33 \%$ (20\% to $40 \%$ ) of inferoposterior infarctions, although it is clinically evident only in $8 \%$ of the cases ${ }^{37-39}$.

The low CO in this situation is due to RV failure to provide proper left ventricular filling. Typical hemodynamic findings are low pulmonary artery and capillary pressures and extremely high central venous pressure. Clinical findings of right ventricular congestion are concomitant with low systemic output. The following conditions should be excluded: pulmonary thromboembolism, cardiac tamponade, constrictive pericarditis, and restrictive cardiomyopathy.
This diagnosis should be remembered in all inferior, posterior or lateral infarctions with low $\mathrm{CO}$ and little evidence of pulmonary congestion. ECG performed with right leads $\left(\mathrm{V}_{3} \mathrm{R}\right.$ and $\mathrm{V}_{4} \mathrm{R}$ ) is the simplest and most reliable method for diagnosis, with $90 \%$ sensitivity and $80 \%$ specificity ${ }^{64}$.

Treatment is based on volume administration in order to achieve proper right ventricular filling and maximum use of the Starling mechanism ${ }^{65}$. Measures that may diminish right ventricular filling, such as the use of vasodilators or diuretics, must be avoided. Hemodynamic monitoring with the Swan-Ganz catheter prevents pulmonary congestion with eventual fluid overload.

Use of sympathomimetic amines is indicated for heart rate maintenance and increase in inotropism. Dopamine increases pulmonary resistance and may impair right ventricular emptying; therefore, it should be used judiciously. Dobutamine does not have this effect.

Atrioventricular conduction disorders not responding to sympathomimetic amines must be treated using a pacemaker. Atrial contraction is important to right ventricular filling maintenance and must be preserved. Restoring sinus rhythm with cardioversion or a sequential pacemaker must not be delayed ${ }^{66,67}$.

IABP is not beneficial in cases of impairment of the RV alone. In cases refractory to clinical treatment, mechanical RV support may be tried as a transitory support until an eventual hemodynamic balance is achieved or as a bridge to heart transplantation.

\section{General treatment strategy}

Hemodynamic support - Immediate pressure and inotropic supports should be started. Using invasive hemodynamic monitoring allows a more rapid and efficient drug adjustment, in order to achieve the best result with minimum side effects.

Mechanical circulatory support - It should be used early, in case of hemodynamic instability, despite adequate pharmacological support. IABP and centrifugal pumps with continuous flow are still the most used devices in this situation.

Thrombolytic agents - The effect of thrombolysis on cardiogenic shock still needs to be better evaluated. However, the more frequent use of thrombolytic agents has brought about a reduction in the incidence of this severe complication of myocardial infarction. Thrombolysis should be used when there is no possibility of using other invasive therapeutic resources.

Cardiac catheterization - It should be performed early, still in the first hours of AMI, allowing the use of another eventual invasive therapeutic intervention, if required.

Coronary angioplasty or revascularization surgery - There is still no consensus on which procedure is more suitable. Therefore, the choice should be based 
upon the particular case and technical availability. It is convenient to emphasize that these are the only procedures already shown to change the natural history of cardiogenic shock.
Heart transplantation - This is an exceptional procedure reserved for refractory shocks. The selection of a particular patient as a heart transplant recipient involves other considerations.

\section{References}

1. Bengtson JR, Goldberg RJ, Kaplan AJ. Cardiogenic shock. In: Califf Mark and Wagner. Ed. - Acute Coronary Care, $2^{\text {nd }}$ ed. St Louis: Mosby Year Book, 1995: 571-83.

2. Carnendran L, Gurunathan R, Webb J, et al. Trends in cardiogenic shock: Report from the Shock Trial Registry, In: Annals of the Annual Meeting of the American College of Cardiology, New Orleans, 1999: 1155-139.

3. Califf RM. Acute myocardial infarction. In: Smith W - Cardiovascular Therapeutics: A Comparison to Braunwald's Heart Disease, ed. Philadelphia: WB Saunders, 1996: 127-69.

4. Califf RM, Bengtson JR. Current concepts: cardiogenic shock. N Engl J Med 1994; 16: 330

5. Gun C, Timerman A, Ramos RF. Choque cardiogênico. Rev Soc Cardiol Est SP 1998; 3: 435-45.

6. Dole WP, O'Rourke RA. Pathophysiology and management of cardiogenic shock. Curr Probl Cardiol 1983; 8: 1-72.

7. Mirowski M, Israel W, Antonopoulos AG, Mower MM, Mendeloff AI. Treatment of myocardial infarction in a community hospital coronary care unit. Experience with 1,246 patients. Arch Intern Med 1978; 138: 210-5.

8. Scheidt S, Ascheim R, Killip T III. Shock after acute myocardial infartion: a clinical and hemodynamic profile. Am J Cardiol 1970; 26: 556-64.

9. Leor J, Goldbourt U, Reicher-Reiss H, Kaplinsky E, Behar S, SPRINT Study Group. Cardiogenic shock complicating acute myocardial infartion in patients without heart failure on admission: incidence, risk factors, and outcome. Am J Med 1993; 94: 265-73.

10. Wackers FJ, Lie KI, Becker AE, Durrer D, Wellens HJ. Coronary artery disease in patients dying from cardiogenic shock or congestive heart failure in the setting of acute myocardial infarction. Br Heart J 1976; 38: 906-10.

11. Frid DJ, Young S, Woodlief LH, Kereiakes DJ, George BS, Bates ER. Undercompensation: the role of the non-infarct related zone in the pathogenesis of cardiogenic shock. Circulation 1990; 82(suppl III): III-430.

12. Hochman JS, LeJemtel T. Management of cardiogenic shock. In: Julian D, Braunwald E, ed. Frontiers in cardiology: management of acute myocardial infarction. Philadelphia: WB Saunders, 1994: 267-90.

13. Hands ME, Rutherford JD, Muller JE, et al. The in-hospital development of cardiogenic shock after myocardial infarction: incidence, preditors of occurrence, outcome and prognostic factors. J Am Coll Cardiol 1989; 14: 40-6.

14. ISIS-3 Third International study of Infarct Survival Collaborative Group (1992) A randomized comparison of Streptokinase vs tissue plasminogen activator vs anistreplase and of aspirin plus heparin vs aspirin alone among 41.299 cases of suspected acute myocardial infarction. Lancet 1992; 339: 753-70.

15. TIMI IIIB Investigators. Effects of tissue plasminogen activator and a comparison of early invasive and conservative strategies in unstable angina and nonQ-wave infarction: results of the TIMI IIIB trial. Circulation 1994; 89: 1545-56.

16. Holmes DR, Bates E. for the Gusto investigators: Cardiogenic shock during myocardial infarction. The Gusto experience with thrombolytic therapy. Circulation 1993; 88: I-25.

17. Harnarayan C, Bennett MA, Pentecost BL, Brewer DB. Quantitative study of infarcted myocardium in cardiogenic shock. Br Heart J 1970; 32: 728-32.

18. Page DL, Caulfield JB, Kastor JA, DeSanctis RW, Sanders CA. Myocardial changes associated with cardiogenic shock. N Engl J Med 1971; 285: 133-7.

19. Pastemak RC, Braunwald E. Acute myocardial infarction. In: Wilson JD, Braunwald E, Isselbacher KJ, eds - Harrison's Principles of Internal Medicine. $12^{\text {th }}$ ed. Vol. 1. New York: McGraw-Hill, 1991: 953-64.

20. Killip IIII, Kimball JT. Treatment of myocardial infarction in a coronary care unit. Am J Cardiol 1967; 20: 457.

21. Beyersdorf F, Buckberg GD. Myocardial protection during surgical intervention for treatment of acute myocardial infarction. Texas Heart Inst J 1992; 19: 26-40.

22. Knobel E, Gonçalves Jr I, Cirenza C - Choque cardiogênico. In: Knobel E, ed. Condutas no Paciente Grave. $2^{\mathrm{a}}$ ed. São Paulo: Atheneu, 1998: 47.

23. Knobel E, Baruzzi ACA, Cirenza C - Infarto agudo do miocárdio. In: Knobel E, ed. Condutas no Paciente Grave. $2^{\text {a }}$ ed. São Paulo: Atheneu, 1998: 151.

24. Forrester JS, Diamano G, Chatterjee K, et al. Medical therapy of acute myocardial infarction by application of hemodynamic subsets. N Engl J Med. 1976; 295: 1356-404.

25. Akamine N, Silva E, Fernandes Jr CJ , Knobel E. Tonometria Gastrointestinal e Perfusão Tecidual. Rev Soc Cardiol Est SP 1998; 3: 520-8.

26. Fernandes Jr CJ, Akamine N, Santos BFC, Cendoroglo Neto M, Knobel E.
Detrimental effects of high dobutamine doses on gastric pHi determinations in a critically Ill septic patient. J Crit Care 1998; 13: 214-15.

27. Akamine N, Fernandes Jr C, Knobel E-Fisiopatologia dos estados de choque. In: Knobel E, ed - Condutas no Paciente Grave. $2^{\mathrm{a}}$ ed. São Paulo: Atheneu, 1998: 3.

28. ACC/AHA Task Force Report Guidelines for the early management of patients with acute myocardial infarction. J Am Coll Cardiol 1990; 16: 249-92.

29. The Task Force of the Management of Acute Myocardial Infarction of the European Society of Cardiology. Acute Myocardial Infarction: Pre-hospital and in-hospital management . Eur Heart J 1996; 89: 1545-56.

30. Kasinski N, Andrei AM, Bueno MAS, Fernandes Jr C. Drogas vasoativas. In: Knobel E, ed. - Condutas no Paciente Grave. $2^{\mathrm{a}}$ ed. São Paulo: Atheneu, 1998: 111.

31. Gillespie TA, Ambos HD, Sobel BE, Roberts R. Effects of dobutamine in patients with acute myocardial infarction. Am J Cardiol 1977; 39: 588-94.

32. Goldstein RA, Passamani ER, Roberts R. A comparison of digoxin and dobutamine in patients with acute infarction and cardiac failure. N Engl J Med 1980; 303: 846-50

33. Klocke RK, Mager G, Kux A, Hopp H-W, Hilger HH. Effects of a twenty-fourhour milrinone infusion in patients with severe heart failure and cardiogenic shock as a function of the hemodynamic initial condition. Am Heart J 1991; 121(suppl): 1965-73

34. Monrad ES, Baim DS, Smith HS, Lanoue AS. Milrinone, dobutamine, and nitroprusside:comparative effects on hemodynamics and myocardial energetic in patients with severe congestive heart failure. Circulation 1986; 73(suppl III): III-168-HI-74.

35. Packer M, Carver JR, Rodeheffer RJ, et al. Effect of oral milrinone on mortality in severe chronic heart failure. N Engl J Med 1991; 325: 1468-75.

36. Knobel E. Management of complicated acute myocardial infarction. In: Roche O, Amaha K, Takeshita TA, eds. - Intensive and Critical Care Medicine. Amsterdam: Elsevier, 1990: 173-80.

37. Zehender M, Kasper W, Kauder E, et al. Right ventricular infarction as an independent predictor of prognosis after acute inferior myocardial infarction. $\mathrm{N}$ Engl J Med 1993; 328: 981-8.

38. Dell'Italia LJ, Starling MR, Crawford MH, Boros BL, Chaudhuri TK, O'Rourke RA. Right ventricular infarction: identification by hemodynamic measurements before and after volume loading and correlation with noninvasive techniques. J Am Coll Cardiol 1984; 4: 931-9.

39. Cohn JN, Guiha NH, Broder MI, Limas CJ. Right ventricular infarction: clinical and hemodynamic features. Am J Cardiol 1974; 33: 209-14.

40. Jugdutt BI, Warnica JW. Intravenous nitroglycerin therapy to limit myocardial infarct size, expansion and complications: effect of timing, dosage, and infarct location. Circulation 1988; 78: 906-19. [Erratum, Circulation 1989; 79: 1151.]

41. Becker LC, Fortuin NJ, Pitt B. Effect of ischemia and antianginal drugs on the distribution of radioactive rnicrospheres in the canine left ventricle. Circ Res $1971 ; 28: 263-9$

42. Leirner AA, Moreira LFP, Stolf NAG. Assistência circulatória mecânica: aspectos atuais. Rev Soc Cardiol Est SP 1998; 3: 464-75.

43. Souza JAM, Cirenza C, Knobel M. In: KnobelE, ed. - Condutas no Paciente Grave. $2^{a}$ ed. São Paulo: Atheneu, 1998: 1401.

44. Scheidt S, Collins M, Goldstein J, Fisher J. Mechanical circulatory assistance with the intraaortic balloon pump and other counterpulsation devices. Prog Cardiovasc Dis 1982; 25: 55-76.

45. Anderson RD, Ohman EM, Holmes DR Jr, et al. Use of intraaortic balloon counterpulsation in patients presenting with cardiogenic shock: observations from the GUSTO-I Study. Global Utilization of Streptokinase and TPA for Occluded Coronary Arteries. J Am Coll Cardiol, 1997; 30: 708-15.

46. Scheidt S, Wilner G, Mueller H, et al. Intra-aortic balloon counterpulsation in cardiogenic shock: report of a co-operative clinical trial. N Engl J Med 1973; 288: 979-84

47. Stone GW, Marsalese D, Brodie BR, et al. A prospective, randomized evaluation of prophylactic intraaortic balloon counterpulsation in high risk patients with acute myocardial infarction treated with primary angioplasty. Second Primary Angioplasty in Myocardial Infarction (PAMI-II) Trial Investigators. J Am Coll Cardiol 1997; 29: 1459-67.

48. Obo H, Kozawa S, Asada T, et al. Emergency percutaneous cardiopulmonary bypass support for acute myocardial infarction. Surg Today 1998; 28: 797-801.

49. Gruppo Italiano per lo Studio della Streptochinasi nell'Infarto Miocardico 
(GISSI). Effectiveness of intravenous thrombolytic treatment in acute myocardial infarction. Lancet 1986; 1: 397-401.

50. ISIS-2 (Second International Study of Infarct Survival) Collaborative Group. Randomised trial of intravenous streptokinase, oral aspirin, both or neithe among 17187 cases of suspected acute myocardial infarction: ISIS 2. Lancet 1988; 2 : 349-60.

51. ISIS-3. (Third International Study of Infarct Survival) Collaborative Group. A randomised comparison of streptokinase vs tissue plasminogen activator vs anistreplase and of aspirin plus heparin vs aspirin alone among 41,299 cases of suspected acute myocardial infarction. Lancet 1992; 339: 753-70.

52. The GUSTO Investigators. An international randomized trial comparing four thrombolytic strategies for acute myocardial infarction. N Engl J Med 1993; 329: 673-82.

53. Satvendra G, Mitchel JF, Kiernan FJ, et al. Adjunctive use of Abciximab improves clinical outcomes in acute myocardial infarction patients presenting with cardiogenic shock. In: Annals of the Annual Meeting of the American College of Cardiology. New Orleans: American College of Cardiology, 1999: 1006-40.

54. Prewitt RM, Gu S, Schick U, Ducas J. Effect of a mechanical vs a pharmacologic increase in aortic pressure on coronary blood flow and thrombolysis induced by IV administration of a thrombolytic agent. Chest 1997; 111: 449-53.

55. Fibrinolytic Therapy Trialist (FTT) Collaborative Group. Indications for fibrinolytic therapy in suspected acute myocardial infarction: Collaborative overview of early mortality and major morbidity results from all randomized trials of more than 1000 patients. Lancet 1994; 343: 315-22.

56. Grines CL, Browne KF, Marco J, et al. A comparison of immediate angioplasty with thrombolytic therapy for acute myocardial infarction. N Engl J Med 1993; 328: 673-9.

57. Zijlstra F, de Boer NIJ, Hoomtje JCA, Reiffers S, Reiber JHC, Suryapranata A. comparison of immediate coronary angioplasty with intravenous streptokinase in acute myocardial infarction. N Engl J Med 1993; 328: 680-4.
58. Gibbons RJ, Holmes DR, Reeder GS, Bailey KR, Hopfenspirger MR, Gersh B Immediate angioplasty compared with the administration of a thrombolytic agent followed by conservative treatment for myocardial infarction. N Engl J Med 1993; 328: 685-91.

59. A clinical trial comparing primary coronary angioplasty with tissue plasminogen activator for acute myocardial infarction. The Global Use of Strategies to Open Occluded Coronary Arteries in Acute Coronary Syndromes (GUSTO IIb) Angioplasty Substudy Investigators. N Engl J Med 1997; 336: 1621-8.

60. O'Neill WW. Angioplasty therapy of cardiogenic shock: Are randomized trials necessary? J Am Coll Cardiol 1992; 19: 915-17.

61. Berger PB, Tuttle RH, Holmes Jr DR, et al. One-year survival among patients with acute myocardial infarction complicated by cardiogenic shock, and its relation to early revascularization: results from the GUSTO-I Trial. Circulation 1999; 99: 873-8.

62. Dunkman WB, Leinbach RC, Buckley MJ, et al. Clinical and hemodynamic results of intraaortic balloon pumping and surgery for cardiogenic shock. Circulation 1972; 46: 465-77.

63. Donatelli F, Benussi S, Triggiani M, Guarracino F, Marchetto G, Grossi A. Surgical treatment for life-threatening acute myocardial infarction: a prospective protocol. Eur J Cardiothorac Surg 1997; 11: 228-33.

64. Lopes-Sendon J, Coma-Canela I, Alcasena S. Eletrocardiographic findings in acute right ventricular infarction: sensitivity and specificity of eletrocardiographic alterations in right precordial leads V4R, V3R, V1, V2 and V3. J Am Coll Cardiol 1985; 6: 1273-9.

65. Guiha NH, Limas CJ, Cohn JN. Predominant right ventricular dysfunction after right ventricular destruction in the dog. Am J Cardiol 1974; 33: 254-8.

66. Topol EJ, Goldschlager N, Ports TA. Hemodynamic benefits of atrial pacing in right ventricular infarction. Ann Intern Med 1982; 96: 594-7.

67. Matangi MF. Temporary physiologic pacing in inferior wall acute myocardial infarction with right ventricular damage. Am J Cardiol 1987; 59: 1207-8. 